\title{
Minimal Spillover of Native Small Mammals From Bornean Tropical Forests Into Adjacent Oil Palm Plantations
}

\author{
Philip M. Chapman ${ }^{1,2 *}$, Robin Loveridge ${ }^{1,3}$, J. Marcus Rowcliffe ${ }^{2}$, Chris Carbone ${ }^{2}$, \\ Henry Bernard ${ }^{4}$, Charles W. Davison ${ }^{1}$ and Robert M. Ewers ${ }^{1}$ \\ ${ }^{1}$ Department of Life Sciences, Imperial College London, Ascot, United Kingdom, ${ }^{2}$ Institute of Zoology, Zoological Society of \\ London, London, United Kingdom, ${ }^{3}$ Department of Environment and Geography, University of York, York, United Kingdom, \\ ${ }^{4}$ Institute for Tropical Biology and Conservation, Universiti Malaysia Sabah, Kota Kinabalu, Malaysia
}

OPEN ACCESS

Edited by:

Janice Ser Huay Lee,

Nanyang Technological University,

Singapore

Reviewed by:

Matthew Scott Luskin

Nanyang Technological University,

Singapore

Lain E. Pardo,

James Cook University, Australia

*Correspondence:

Philip M. Chapman

phil.chapman558@gmail.com

Specialty section:

This article was submitted to

Tropical Forests,

a section of the journa

Frontiers in Forests and Global

Change

Received: 23 November 2018 Accepted: 14 February 2019

Published: 15 March 2019

Citation:

Chapman PM, Loveridge $R$,

Rowcliffe JM, Carbone C, Bernard H,

Davison CW and Ewers RM (2019)

Minimal Spillover of Native Small

Mammals From Bornean Tropical

Forests Into Adjacent Oil Palm

Plantations.

Front. For. Glob. Change 2:2.

doi: 10.3389/ffgc.2019.00002
In the face of rapid tropical agricultural expansion, preservation of tropical forest remnants is crucially important. Forest remnants often about the edges of new or established plantations, so landscape-level conservation requires an understanding of the balance between ecosystem services and disservices provided by forest, including potential crop yield reductions caused by species such as rodents, an important pest group in oil palm plantations. However, very little is known about the scale of any spillover of native species which inhabit forest into adjacent agricultural areas. We examined the distribution and behaviour of small mammals across an edge separating logged tropical forest and oil palm plantations in Sabah, Malaysian Borneo, using a dual approach. We used a trapping grid to reveal patterns of species relative abundance across the forest-plantation edge, and tracked individuals of forest species using a spool-and-line. We uncovered little evidence that the native forest small mammal community crosses the edge and uses the plantation, although two invasive small mammal species were found across the whole edge gradient. Of 10 forest species detected, we found only the adaptable murid Maxomys whiteheadi in the plantation, where it persisted at low abundances across all sampling points, including in the plantation interior control site. This pattern is more consistent with persistence of $M$. whiteheadi throughout plantations than with spill-over from forest fragments. On the forest side, observed species richness of small mammals increased with distance into the interior, suggesting a negative edge effect may exist within forest remnants. Of 23 successfully tracked small mammals, only one M. whiteheadi crossed the forest-plantation edge, and overall, this species was significantly repelled from crossing into plantation habitat. Our results suggest that spillover of native small mammals contributes little to oil palm damage close to forestplantation edges, but that oil palm negatively impacts small mammal populations within adjacent forest remnants.

Keywords: habitat edge, oil palm, small mammals, spillover effect, forest, agricultural pests 


\section{INTRODUCTION}

Maximising the remaining area of tropical forest amid agricultural expansion is a priority for conservation (Gibson et al., 2011; Wilcove et al., 2013), especially in Southeast Asia where the expansion of oil palm (Elaeis guineensis) continues to threaten one of the world's great biodiversity hotspots (Fitzherbert et al., 2008; Wilcove et al., 2013; Yue et al., 2015; Vijay et al., 2016). Most of Southeast Asia's remaining primary forest is already protected, but this is considered insufficient for the long-term persistence of many species and their movements. Future conservation efforts are increasingly focused on previously logged forests within timber concessions, and fragmented forests in agricultural landscapes-areas with limited residual economic value and poor legal protection (Reynolds et al., 2011). A key challenge in creating and maintaining protected areas adjacent to plantation agriculture is understanding and managing spillover of plants and animals between the two habitat types. Spillover may involve transient dispersal and foraging movements in either direction across the habitat boundary, and may involve species providing ecosystem services such as pest control (Koh, 2008; Lucey et al., 2014; Nurdiansyah et al., 2016); or ecosystem disservices such as crop damage, which harms yields and therefore profits (Zhang et al., 2007). Depending on the organisms involved, there may exist a range of ecological effects from net benefit to net cost on either habitat close to the boundary (Rand et al., 2006; Blitzer et al., 2012; Edwards et al., 2014). The way that plantation workers, landowners and policymakers perceive this service-disservice balance is important, as ecosystem services provided may be subtle and complex. Even if there is a net positive effect of retaining forest remnants in plantations, if stakeholders regard them as pest reservoirs they are likely to resist efforts to conserve those remnants, contributing to local and global losses of biodiversity from tropical deforestation (Bradshaw et al., 2009; Wilcove et al., 2013).

Forest remnants may act as a source of pests in two different ways. First, the remnants may harbour increased abundance of generalist, sometimes invasive pests (e.g., Luskin et al., 2014, 2017). Such species are often already prevalent in the wider landscape and remnants may provide them with undisturbed breeding space and favourable microhabitats that shield them from pesticide control (White et al., 1997; Tweheyo et al., 2005; Valantin-Morison et al., 2007; Amici et al., 2012). Second, forestdependent species might cross the forest-plantation edge and forage in plantations, thus adding novel pest species to the plantation community (Hill, 1997, 2000; Naughton-Treves, 1998; Saj et al., 2001; Strum, 2010). This spillover of forest species may be particularly pronounced in years of extreme resource limitation in forests, such as famines between mast-fruiting events. For those species highly dependent on such inter-annually variable food resources, the net benefits of spilling over the edge may be much increased at these times (Luskin et al., 2017). Where forest species do cross into plantations and are susceptible to pre-existing intensive pest control measures, their populations may be reduced near the edge and thus the plantation can act as a sink habitat and an "ecological trap" (Forbes and Theberge,
1996; Woodroffe and Ginsberg, 1998; Lamb et al., 2017). In a landscape where most forest remnants are small and isolated, this could contribute to extirpation of vulnerable species at a landscape scale. Conversely, species with low vulnerability to pest control can increase dramatically in abundance, causing cascading negative effects on forest remnants and disrupting food webs (Luskin et al., 2017). The identity of communities spilling over at the forest-plantation edge is therefore important from both a conservation and an economic standpoint. Despite this, evidence for the contribution of tropical forest species to agricultural ecosystem disservices remains lacking.

Murid rodents are among the most economically significant pest groups in many temperate and tropical crops, including Southeast Asian oil palm (Lee and Kdmarudin, 1990; Wood, 1994; Puan et al., 2011). Spillover of murids from adjacent natural ecosystems appears to occur in many other crop systems, with several studies reporting that variation in crop damage near edges is predicted by the extent of surrounding natural variation (Wood, 1994). Our own informal conversations with oil palm plantation managerial staff in Sabah, Malaysian Borneo, partly support this view: Most managers we surveyed perceived that crop damage by rodents was greater nearest forest-plantation edges. To our knowledge, spillover effects have rarely been investigated explicitly for small mammals, and not at all in oil palm agriculture. We therefore do not know if managers' perceptions of spillover are supported by evidence.

Most available literature on oil palm pest species focuses on economic impacts and chemical control (Wood, 1984; Wood and Liau, 1984a,b; Wood and Chung, 1990; Hafidzi and Saayon, 2001; Andru et al., 2013) rather than broader aspects of their ecology (but see Buckle et al., 1997). The literature is also heavily biased towards established pest species, generally a handful of invasive, open-country generalists of the genus Rattus, particularly the Malaysian Field Rat $R$. tiomanicus (Wood, 1984; Wood and Liau, 1984a,b; Buckle et al., 1997; Wood and Fee, 2003; Puan et al., 2011; Phua et al., 2017). Conversely, spillover of forest small mammal species into plantations has hardly been investigated. These species, including murids, squirrels, and treeshrews, remain at high abundances within heavily-logged forest adjoining oil palm landscapes (Wells et al., 2007; Bernard et al., 2009; Wearn et al., 2017; Chapman et al., 2018), and are easily trapped using oil palm fruit as bait (pers. obs.). Therefore, there is potential for the forest community to spill over into adjacent plantations and increase existing levels of fruit predation and yield damage.

We found only three studies that reported spillover of forest small mammal species into oil palm plantations. Combined, these studies recorded the murids Sundamys muelleri (Muller's Rat), Maxomys whiteheadi (Whitehead's Rat), Maxomys surifer (Red Spiny Rat), and Niviventer cremoriventer (Dark-Tailed Tree Rat) (Rajaratnam et al., 2007; Bernard et al., 2009; Phua et al., 2017). Of these species, only $M$. whiteheadii was recorded relatively frequently. Across the three studies combined, only seven individuals of the remaining species were recorded in plantations. Neither study explicitly investigated the spatial scale of this spillover of forest-dependent small mammal populations, but individuals were detected up to $200 \mathrm{~m}$ away from forest 
edges. Together, these results suggest that individual forest small mammals can and do cross habitat edges into plantations, but that many species might be impeded to some degree from doing so. However, we found no studies of individual movements across these edges, and it is unclear to what extent the forest-plantation edge forms a barrier for small mammals.

The benefits of crossing the edge and foraging within oil palm plantations relative to the costs should depend on the microhabitat preferences of the forest small mammal species concerned, and on the characteristics of the plantation itself. Although Southeast Asian forest small mammals inhabit a variety of foraging niches (Wells et al., 2006; Loveridge et al., 2016), most species prefer sheltered environments (Bernard, 2004). Younger plantations generally exhibit denser herbaceous ground vegetation (Luskin and Potts, 2011) and lower, more accessible fruiting crowns (Puan et al., 2011), and appear to support higher densities of invasive Rattus spp. accordingly (Puan et al., 2011; Phua et al., 2017). However, it is unknown whether these plantation characteristics also predict the spatial extent of native small mammal spillover or relative abundance within plantations.

In this study, we investigated the distribution and movement of forest small mammals at forest-plantation edges in Sabah, Malaysian Borneo, using a dual approach. First, we used a live-trapping grid spanning an edge between forest and oil palm plantation to examine broad patterns of community distribution across the edge. We tested the hypothesis that most or all forest small mammal species will occur in the plantation, but that: 1 . Capture rates of all species will decline with increasing distance into the plantation; 2 . The distance at which capture rates decline to zero will vary between species; and 3. Abundance of species in plantations will be predicted by plantation structure and management. Second, we used spooland-line tracking of individual forest small mammals captured at the edge, or just inside the forest, to examine edge crossing behaviour and movement patterns within plantations. We used null modelling to test whether individuals cross the edge more or less than expected by chance. Filling these knowledge gaps will help to quantify the distribution and potential economic effects of forest small mammals at the edges of plantations, and the ecological effects of oil palm edges on neighbouring forest small mammal communities. Therefore, these findings will serve to inform both economic and biodiversity arguments as to the costs and benefits of retaining forest remnants in an oil palm landscape.

\section{METHODS}

\section{Study Areas}

We collected field data within the 1 million hectare Yayasan Sabah Forest Management Area in Sabah, Malaysian Borneo, which comprises a patchwork of protected primary dipterocarp forest, selective logging concessions and oil palm plantations (Reynolds et al., 2011). We sampled forest-plantation edges in two locations: the experimental landscape at the Stability of Altered Forest Ecosystems (SAFE) project, a landscape-scale deforestation experiment (Ewers et al., 2011; N4 $41^{\prime} 58^{\prime \prime}$, E117 $\left.37^{\prime} 40^{\prime \prime}\right)$, and a second area of forest $\sim 23 \mathrm{~km}$ west-southwest (N4 $\left.38^{\prime} 26^{\prime \prime}, \mathrm{E} 117^{\circ} 26^{\prime} 09^{\prime \prime}\right)$. At both edge locations, the forest comprised $>1,000$ ha tracts of heavily-logged forest, with continuous forest cover extending for $\geq 1 \mathrm{~km}$ behind the edge, and featured a structure typical of logged forest in the region, with few large trees and a dense understorey of vines and herbaceous plants (Pfeifer et al., 2016). Our forest study areas directly adjoined oil palm plantations (managed by Benta Wawasan Sdn Bhd), which were planted between 2004 and 2013, and therefore ranged from young but established plantations (c. 4 years old) to mature plantations (c. 13 years old). Oil palm trees were planted at an average density of 120-140 palms.ha1 , and we chose plantations that were managed with moderate intensity, typical of the wider region. This was defined by control of ground flora, epiphyte cover allowed to persist on palm trunks, and unplanted areas such as stream gullies that had been allowed to develop extensive ground cover of kudzu (Pueraria sp., young plantations) or native herbs (older plantations) to limit soil runoff.

\section{Sample Sites}

We sampled small $(<1 \mathrm{~kg})$ mammal communities at nine sites spread between the two edge locations: six at the SAFE project edge, and three at the second edge to the WSW. We also sampled at one plantation-interior control site (at the WSW area), which was $>1.5 \mathrm{~km}$ from the forest edge at the second location. Within a study area, sites were located along the same forest edge, however we spaced neighbouring sites $\geq 300$ m apart (range: 308 $761 \mathrm{~m}$ ) to minimize interactions between sampled communities and maintain independence between sites. This distance is several times the maximum home range radius of Leopoldamys sabanus, the largest and widest-ranging murid likely to be encountered (Wells et al., 2008). We preferentially selected sites with a straight forest edge, as this minimised error in the measurement of distance from the edge to the trapping points inside the forest. We also chose sites with a cleared, herbicide-treated buffer strip separating the herbaceous forest understorey vegetation (or the base of the trees) from the ground flora in the area covered by the plantation. This strip varied from 2 to $5 \mathrm{~m}$ wide, and invariably contained a small two-strand electric livestock fence, and minimal or no ground vegetation. We selected this feature because: (1) this management technique was predominant in our study system and the landscape as a whole; (2) the measurement of the position of the forest-plantation edge is relatively discrete and unambiguous, allowing us to precisely locate traps at a defined edge position; and (3) we could control for the presence and density of "bridges" of ground vegetation linking the ground cover of the forest remnant and the oil palm plantation. To further control for the physical structure of the edge, we rejected sites where the strip was $>5 \mathrm{~m}$ wide, included an active access track, or was significantly eroded into gullies by rainwater runoff, as these features may bias movement of individuals near the edge.

\section{Trapping}

All animal trapping and handling procedures in this study were carried out in accordance with the guidelines published by the American Society of Mammalogists (Sikes et al., 2011), and 
before starting fieldwork, all trapping and handling procedures were reviewed and approved by two ethics committees (Imperial College London's Animal Welfare and Ethical Review Body, and the Zoological Society of London's Ethics Committee). At each edge site, we set up a live-trapping grid comprising 36 trap points in nine lines of four with $23 \mathrm{~m}$ spacing between lines, spanning the edge from $46 \mathrm{~m}$ inside the forest to $138 \mathrm{~m}$ inside the plantation, with one trap line at $0 \mathrm{~m}$, i.e., directly on the forest-plantation edge (total area covered $=8,280 \mathrm{~m}^{2}$, see Figure 1). We designed the grid carefully to avoid biasing animal movement towards the edge, and particularly avoided cutting access trails perpendicularly into the forest toward each trap, as this potentially provides an easy route from interior to edge. Instead, we made a single perpendicular access trail to one side of the grid, and accessed traps via side trails parallel to the edge, with the first trap appearing $>5 \mathrm{~m}$ from the perpendicular access trail (Figure 1). We took care to cut the minimum vegetation required to access traps. At each trapping point we placed one locally made "Tomahawk" style wire mesh cage trap $(28 \times 18$ $\times 12 \mathrm{~cm}$ ), placing traps preferentially in dense ground cover or undergrowth, and baiting with a ripe oil palm fruit. Although this bait is clearly abundant in the environment, previous experience in this study system has shown that palm fruit is still effective at capturing small mammals in oil palm plantations as well as forest (e.g., Wearn et al., 2017). This is possibly due to the preference of small mammals to feed in sheltered spaces, meaning that bait inside an enclosed trap remains more attractive than bait in the wider environment. We therefore covered traps with a black plastic wrapping, which also sheltered captured animals from rain and excess heat. The control site did not straddle an edge, but we designed it to retain the same area covered and trap density (one trap per $3.78 \mathrm{~m}^{2}$ ).

We trapped at each grid for 3 days and nights, with checking carried out daily in the early morning to avoid exposing animals to excess heat, and traps set again in mid-afternoon. Sick or injured animals were released without processing, however we anaesthetised all other newly captured animals using diethyl ether, identified to species, aged, and sexed where possible, and uniquely marked them with a Passive Integrated Transponder (PIT) tag (Francis Scientific Instruments, Cambridge, UK) to enable individual ID of recaptures. To support uncertain ID, aging and sexing, we also took biometrics (hind foot and ear length, ano-genital distance, and weight). We recorded the ID and location of all recaptures, then released all animals at their capture location.

\section{Spool-and-Line Tracking}

To examine patterns of individual movement at edges, we trapped on the three trap lines of each grid covering the forest and edge (i.e., the lines at 0,23 , and $46 \mathrm{~m}$, see Figure 1) for an additional three nights. To maximize capture rates, we added two extra trapping lines interspersed between the existing lines (at 11.5 and $34.5 \mathrm{~m}$ into the forest, Figure 1). Since most Bornean small mammals are nocturnal, we processed captures and released them for tracking with several hours of night remaining, in order to capture representative space use behaviour. We set traps at dusk, and processed captures between
21:00 and 22:00, remaining $>50 \mathrm{~m}$ away from the grid during the intervening period to minimise disturbance. To track released small mammals, we used a spool-and-line device following Loveridge et al. (2016). We covered an industrial nylon cocoon bobbin (Danfield Ltd, Lancashire, UK) with a cling film wrapping to ensure that it unravels and detaches cleanly, and then wrapped it with cloth tape and attached it to the back of the small mammal using cyanoacrylate glue. Following established procedures for radio tracking (e.g., Kenwood, 2000) we unwound each spool so that the total mass including wrapping did not exceed $5 \%$ of the animal's body weight. Once each animal had fully recovered from anaesthesia, we released it, having first tied the loose bobbin end to the trap or adjacent vegetation at the trapping site. The bobbin is coreless and unravels freely from the inside outward, so the animal moves with minimal resistance and the outside end detaches easily once the animal has moved the entire length of the thread (Miles et al., 1981). We took considerable care to release animals as simultaneously as possible on the grid and exit the area quietly and rapidly in order to avoid disturbing previously-released individuals, and we did not spool more than three animals per night. The following morning we followed and collected the spool threads, measuring the total tracked distance, and recording whether animals crossed the edge. For animals which did not cross, we recorded whether they approached within $5 \mathrm{~m}$ of the edge (defined as moving towards the edge from within the forest and remaining $<5 \mathrm{~m}$ from the edge for at least $5 \mathrm{~m}$ travelled distance). Since animals can only cross the edge if they move further than the distance from their release point to the edge, and because small animal movements are seldom linear, we only retained for analysis those paths where the animal had travelled at least the distance from its release point to the edge, plus $20 \%$ extra. In the case of animals released at $0 \mathrm{~m}$, we discarded paths where the animal travelled $<20$ m overall.

\section{Vegetation Covariates}

To investigate whether plantation characteristics affect the spillover of forest-dependent small mammals, we measured habitat variables at each of the 24 trap points of the grid covering the plantation side of the edge (Figure 1), ensuring that this coincided with trapping. First, for all trap locations we recorded a categorical trap location variable, describing whether the location was in a stand of oil palm trees (at least one trunk within $5 \mathrm{~m}$ ), open bare ground, or open ground with ground covering vegetation. For the subset of locations on each grid (mean $=20.9 \pm 0.81$ ) which fell within a stand of palms, we measured four characteristics of the closest palm to the trap: 1. Trunk height (to the underside of the branches level with the crown), using a laser rangefinder (Bosch $\mathrm{GmbH}$, Stuttgart, Germany); 2. Ground vegetation cover within a $5 \mathrm{~m}$ radius of the trunk base, using a four-level categorical index, corresponding to $25 \%$ increments $(1=0-25 \%$ cover, $2=25-$ $50 \%$ cover, $3=50-75 \%$ cover, and $4=75-100 \%$ cover $) ; 3$. The number of visible infructescences; and 4. Presence/absence of ripe fruit at ground level. Frequently, harvesting was occurring in our study sites during trapping. Harvested fruit will have been previously available to small mammals, therefore our count 


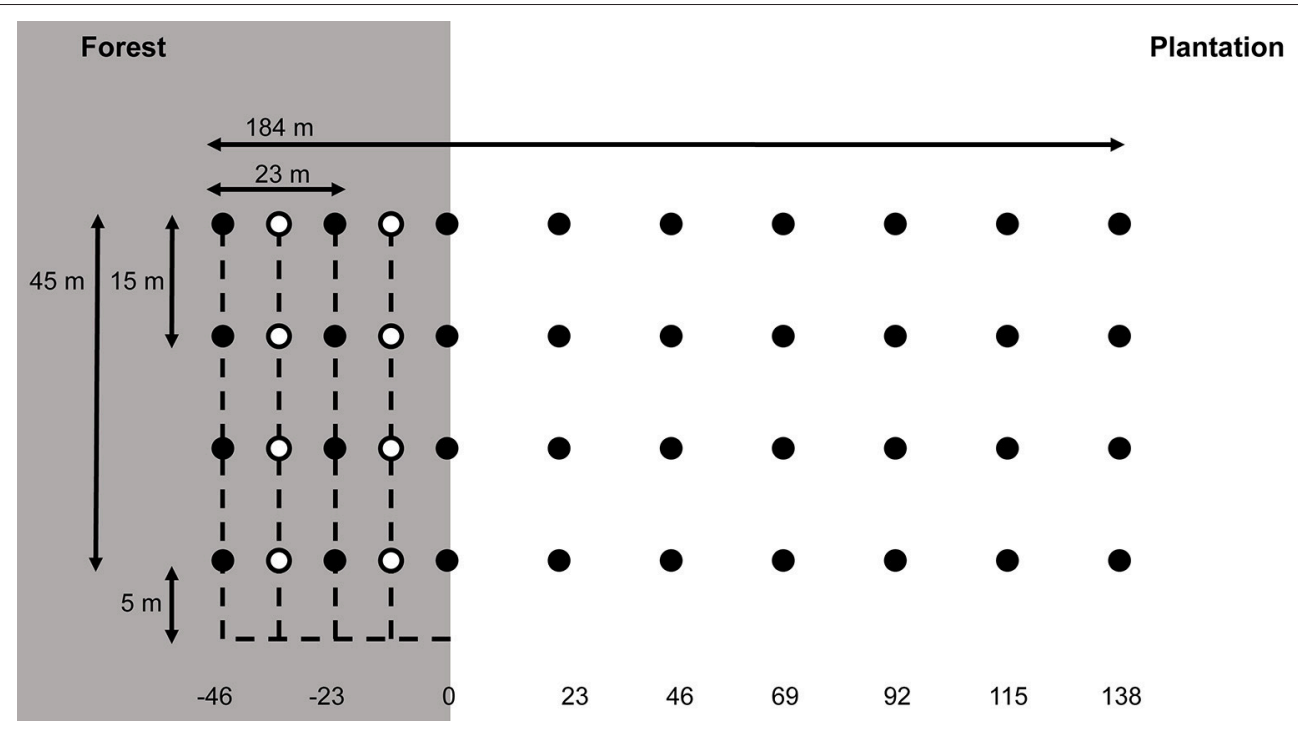

FIGURE 1 | Schematic of the grid trapping design, showing the arrangement of trapping points (filled circles) in the forest (grey shaded area) and plantation (white area). Distances of trapping lines from the edge (in metres), as referred to in the text, are shown at bottom, with the line at $0 \mathrm{~m}$ being situated exactly on the edge. Open circles: extra trapping lines used for the individual movement portion of the study, interspersed between the forest trapping lines at -11.5 and $-34.5 \mathrm{~m}$. Dashed lines: Access trails (see text).

of infructescences included obviously fresh cut scars, where infructescences had been removed within the preceding 24 hours.

\section{Analyses}

We carried out all analyses using R v.3.5.0 (R Core Team, 2018). To investigate the extent of the spillover effect, we first identified which species that were trapped in forest were also trapped in oil palm. We defined the spillover extent of each species as the distance from the edge over which abundance is elevated above that species' background abundance in the oil palm plantation [following conceptually similar approaches in e.g., (Chen et al., 1992; Brand and George, 2001; Hylander, 2005)]. We used capture rate of each species as a proxy for abundance, pooling captures of individuals (i.e., discarding subsequent recaptures) over the three trapping nights at each trap point. To statistically test spillover extent of each species, we tested for the difference between mean capture rate at each trap line and capture rate in the interior oil palm control plot, using a generalised linear mixed model (Poisson error, log link) fitted in package lme4 (Bates et al., 2015). Where capture rates ceased to differ from that within the control plot, we took this distance to represent the limit of the species spillover into the plantation. Where a species was trapped within the plantation at the edge sites but not at the control site, we took the species spillover limit to be the distance at which capture rates ceased to differ from zero.

To test whether the characteristics of oil palm plantations predicted capture rates of each species within the plantation, we subsetted the trapping data to only include captures from the 24 traps in each grid on the plantation side of the edge (see Figure 1). We then modelled pooled capture rates of each species against our plantation structure variables, using generalised linear models (Poisson error, log link) in two stages.
First, we modelled capture rates across all plantation traps against the categorical trap location variable (oil palm stand/open bare ground/ground cover vegetation) to test whether this basic plantation characteristic predicted capture rates. Then, we subsetted further, to only include trap points within a stand of oil palm trees (mean $=20.9 \pm 0.81$ locations per grid). We modelled pooled capture rates against the detailed habitat quality variables (oil palm tree height, ground cover, fruit bunch count, and presence/absence of ripe or fallen fruit). We took a model selection approach, fitting models of increasing complexity. First, we fitted each variable separately, then models with the terms added sequentially, then models with all combinations of twoway interactions. We selected the best-fitting model for each species based on Aikake's Information Criterion (AIC), selecting the model with lowest AIC in each case.

To investigate whether edges impede individual small mammal movement, we used a null modelling approach to compare the observed proportion of individuals crossing edges with null proportions derived from simulated random small mammal paths. First, we grouped our observed small mammal paths by species and distance released from the edge. For each species, at each release distance, we recorded the observed proportions of individuals which crossed the edge. We assumed that small mammal movement trajectories can be simplified to a series of step lengths in centimetres, connected by relative turning angles in degrees (following e.g., Almeida et al., 2015; Loveridge et al., 2016). To simulate random paths and generate null crossing proportions, we extracted species-specific distributions of these step lengths and turning angles from Loveridge et al. (2016). These authors made detailed measurements of small mammal paths in continuous selectively logged forest within our study landscape. This forest was $>1 \mathrm{~km}$ away from the 
nearest forest-plantation edge, but was analogous in logging intensity and vegetation structure to the forest at our study edges (Loveridge et al., 2016). We then iteratively constructed null paths by sampling randomly from these distributions of step lengths and turning angles.

For each of the observed species $\times$ distance groups, we constructed 1,000 null groups, each composed of null paths exactly corresponding in number and total travelled distance to the individuals in the observed group. We then plotted these null paths in Cartesian $\mathrm{x}-\mathrm{y}$ space, and calculated the proportion of the paths which crossed the edge at the relevant distance from the release point. For example, given an observed group of five individuals released $23 \mathrm{~m}$ from the edge, we constructed a group of five null paths exactly matching the observed paths in travelled distances, then iterated this 1,000 times, recording for each group of five null paths the proportion which moved $\geq 23 \mathrm{~m}$ along one axis from the release point. To eliminate any directional bias in the starting heading of the null paths, we randomly varied the orientation of the axis along which the path should exceed the critical distance, switching between $\mathrm{x}, \mathrm{y},-\mathrm{x}$, and $-\mathrm{y}$. This process produced a distribution of null crossing proportions for each species $\times$ distance group: we then calculated significance by comparing the observed proportion of edge crossers with the 0.025 and $97.5 \%$ quantiles of this null distribution, to determine whether there was less than a 5\% chance that the observed proportion of crossers was drawn from the expected distribution.

\section{RESULTS}

\section{Small Mammal Species Distribution Across the Forest-Plantation Edge}

Across our 10 trapping grids, we ran 36 traps per grid for 3 days each, giving a total trapping effort of 1,080 trap-nights. In 230 capture events, we captured 215 individual small mammals comprising 12 species (21\% trap success rate, see Table 1). Capture rates of both species and individuals increased through time more quickly in the forest trap lines than in the oil palm plantation trap lines (Figure S1). All 12 species occurred inside the forest, and comprised 10 native murids, squirrels and treeshrews, plus two invasive murids (Black Rat, Rattus rattus and Polynesian Rat $R$. exulans, see Table 1). In the plantation, we only caught these two invasive species, plus the native murid Whitehead's Rat ( $M$. whiteheadi). We therefore caught no species which were confined to the plantation, but nine that were confined to the forest. With the exception of $M$. whiteheadi, no native forest-dependent small mammal species were trapped at any distance into the plantation. Of the remaining nine native species captured in forest, four were captured immediately at the forest-plantation edge $(0 \mathrm{~m})$, a further three were only captured $23 \mathrm{~m}$ into the forest and two species were only captured at $46 \mathrm{~m}$ into the forest (Table 1).

\section{Capture Rates of Murids Across the Forest-Plantation Edge}

The three murid species which were present in plantation showed different patterns of abundance across the forest-plantation edge

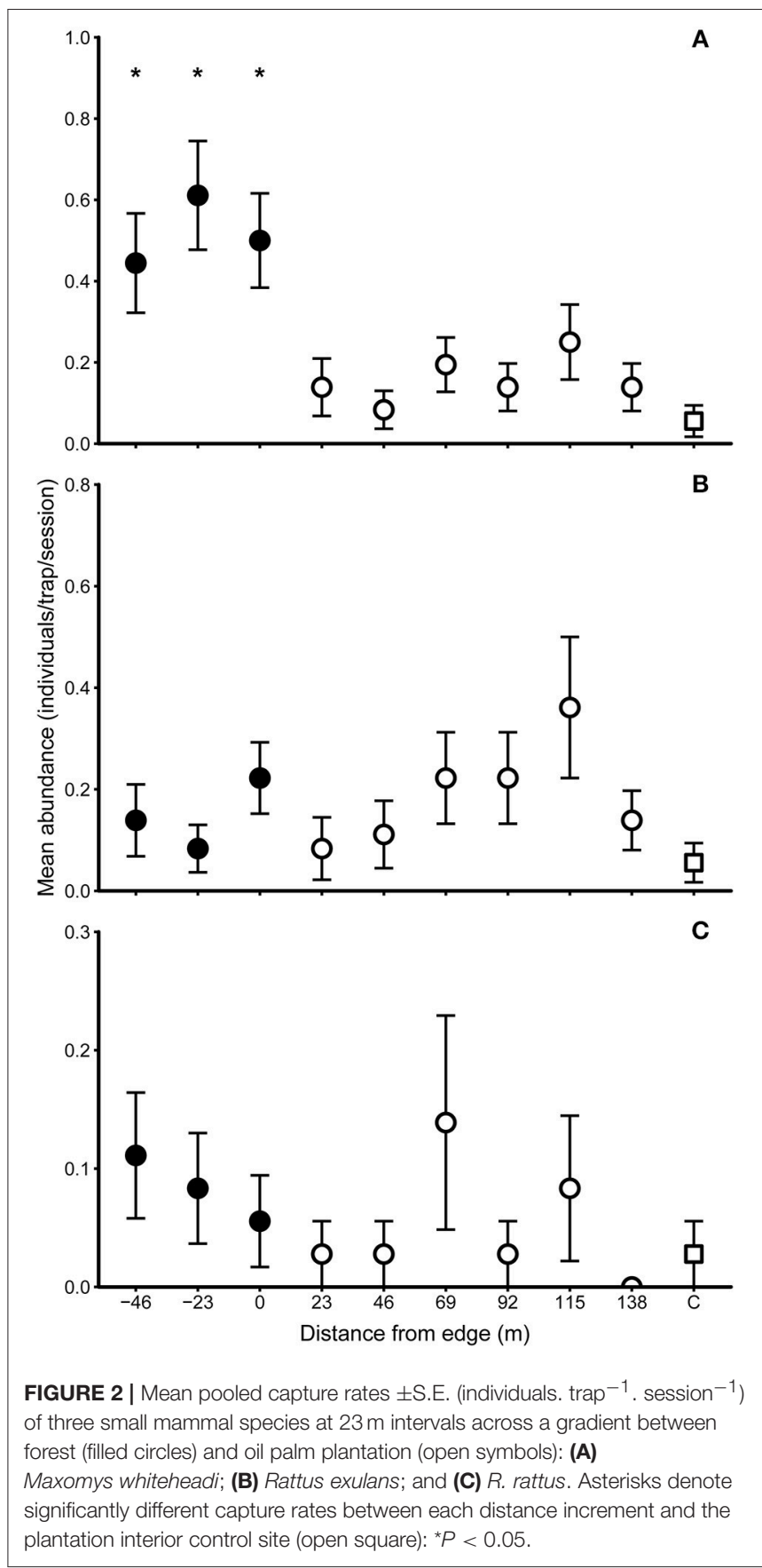

(Figure 2). Compared to the oil palm control site, M. whiteheadi was more abundant (higher capture rate) in the forest trap lines, i.e., at $-46 \mathrm{~m}(2.00, \mathrm{Z}=1.994, P=0.04)$, at $-23 \mathrm{~m}$ (2.32, $\mathrm{Z}=2.33, P=0.02)$, and at $0 \mathrm{~m}(2.12, \mathrm{Z}=2.12, P=0.03)$ (generalised linear mixed models with Poisson error and log link). However, capture rates of $M$. whiteheadi did not differ from the control value at any distance into the plantation (Figure 2A). By contrast, Rattus exulans had similar capture rates in forest and oil palm, and did not differ from the control value throughout the edge transect (Figure 2B). R. rattus was scarce and unevenly 
TABLE 1 | Total unique small mammal captures across our edge gradient by species and distance from the edge.

\begin{tabular}{|c|c|c|c|c|c|c|c|c|c|c|c|c|c|}
\hline \multirow[t]{2}{*}{ Species } & \multicolumn{3}{|c|}{ Forest } & \multicolumn{7}{|c|}{ Plantation } & \multicolumn{2}{|c|}{ Subtotals } & \multirow[t]{2}{*}{ Total } \\
\hline & $-46 m$ & $-23 m$ & $0 \mathrm{~m}$ & $23 \mathrm{~m}$ & $46 \mathrm{~m}$ & $69 \mathrm{~m}$ & $92 \mathrm{~m}$ & $115 \mathrm{~m}$ & $138 \mathrm{~m}$ & Control & Forest & Plantation & \\
\hline $\begin{array}{l}\text { Four-striped ground } \\
\text { squirrel } \\
\text { Lariscus hosei }\end{array}$ & 1 & - & - & - & - & - & - & - & - & - & 1 & 0 & 1 \\
\hline $\begin{array}{l}\text { Long-tailed giant rat } \\
\text { Leopoldamys sabanus }\end{array}$ & 1 & - & - & - & - & - & - & - & - & - & 1 & 0 & 1 \\
\hline $\begin{array}{l}\text { Red spiny rat } \\
\text { Maxomys surifer }\end{array}$ & 3 & 2 & - & - & - & - & - & - & - & - & 5 & 0 & 5 \\
\hline $\begin{array}{l}\text { Whitehead's rat } \\
\text { Maxomys whiteheadi }\end{array}$ & 16 & 23 & 18 & 5 & 3 & 7 & 5 & 9 & 5 & 2 & 57 & 36 & 93 \\
\hline $\begin{array}{l}\text { Dark-tailed tree rat } \\
\text { Niviventer cremoriventer }\end{array}$ & 1 & 1 & 3 & - & - & - & - & - & - & - & 5 & 0 & 5 \\
\hline $\begin{array}{l}{ }^{\dagger} \text { Polynesian rat } \\
\text { Rattus exulans }\end{array}$ & 5 & 4 & 8 & 3 & 4 & 8 & 8 & 13 & 5 & 2 & 17 & 43 & 60 \\
\hline $\begin{array}{l}{ }^{t_{\text {Black rat }}} \\
\text { Rattus rattus diardii }\end{array}$ & 4 & 3 & 2 & 1 & 1 & 5 & 1 & 3 & - & 1 & 9 & 12 & 21 \\
\hline $\begin{array}{l}\text { Horse-tailed squirrel } \\
\text { Sundasciurus hippurus }\end{array}$ & - & 2 & & - & - & - & - & - & - & - & 2 & 0 & 2 \\
\hline $\begin{array}{l}\text { Low's squirrel } \\
\text { Sundasciurus lowii }\end{array}$ & 3 & 2 & 1 & - & - & - & - & - & - & - & 6 & 0 & 6 \\
\hline $\begin{array}{l}\text { Slender treeshrew } \\
\text { Tupaia gracilis }\end{array}$ & - & - & 1 & - & - & - & - & - & - & - & 1 & 0 & 1 \\
\hline $\begin{array}{l}\text { Common treeshrew } \\
\text { Tupaia longipes }\end{array}$ & 8 & 4 & 3 & - & - & - & - & - & - & - & 15 & 0 & 15 \\
\hline $\begin{array}{l}\text { Large treeshrew } \\
\text { Tupaia tana }\end{array}$ & 2 & 3 & - & - & - & - & - & - & - & - & 5 & 0 & 5 \\
\hline Total & 44 & 44 & 36 & 9 & 8 & 20 & 14 & 25 & 10 & 5 & 124 & 91 & 215 \\
\hline
\end{tabular}

The edge is at $0 \mathrm{~m}$, while negative distances denote forest trap lines and positive distances denote plantation trap lines. Crosses ${ }^{\dagger}$ denote invasive plantation generalist species. Common names follow Payne and Francis (1985).

distributed across the edge transects (e.g., this species was not caught at $138 \mathrm{~m}$ ), and its capture rates also did not differ from the control value throughout the edge transect (Figure 2C).

\section{Influence of Plantation Habitat on Murid Capture Rates}

Within the plantation, capture rates of both $M$. whiteheadi and $R$. exulans were better predicted by characteristics of the plantation habitat than by the distance from the edge. In both cases, the best-performing model was a simple model with only oil palm tree height included, which negatively predicted capture rates of both $M$. whiteheadi (generalised linear model with Poisson error and log link; $t=-3.25, p=0.001$ ) and $R$. exulans (generalised linear model with quasipoisson error and log link, $t=-2.06$, $p=0.009$ ). The capture rates of $R$. rattus were not significantly predicted by any habitat variables or distance from the edge (i.e., its capture rates were best predicted by a null model).

\section{Individual Edge Crossing and Movement}

We attached spools to 39 individual small mammals (of which 14 had previously been captured and PIT-tagged in the community distribution section of the study). Of these, 23 individuals were tracked for a distance at least $120 \%$ of the distance to the edge, including $18 \mathrm{M}$. whiteheadi, three $R$. rattus, one $N$. cremoriventer, and one $M$. surifer. Ten of the 23 individuals approached within $5 \mathrm{~m}$ of the edge (from within the forest). Six $M$. whiteheadi and one $N$. cremoriventer made apparent foraging or ranging movements to the extreme edge of the forest vegetation (i.e., to $0 \mathrm{~m}$ ) for an apparently prolonged period ( $>10 \mathrm{~m}$ travelled). Only one $M$. whiteheadi crossed the edge, an adult female, which was released at $11.5 \mathrm{~m}$ into the forest. This animal made c. $40 \mathrm{~m}$ of apparent foraging movements within the forest, before penetrating the plantation to a total straight-line distance of $11.5 \mathrm{~m}$ (covered distance $=27.85 \mathrm{~m}$ ) before shedding the spool. Due to the low sample sizes of most tracked species, we could only apply null modelling to M. whiteheadi ( $n=18$ individuals). Sample sizes were also too low at most distances from the edge to separately construct quantiles and estimate significance for the difference between the observed and expected proportions of edge crossers. Therefore, after simulating the random path groups at each distance from the edge, we pooled these into an "interior" group of 10 simulated individuals (released $\geq 23 \mathrm{~m}$ from the edge) and a "near-edge" group of eight individuals (released at $\leq 11.5 \mathrm{~m}$ from the edge). Small mammals in the "interior" group were no more or less likely than random expectation to cross the edge (Observed proportion $=0 ; 2.5$ and $97.5 \%$ quantiles of simulated distribution $=0,0.0833$ ). However, small mammals 
from the "near-edge" group were significantly less likely to cross than random expectation (Observed proportion $=0.125 ; 2.5$ and $97.5 \%$ quantiles $=0.25,0.75)$.

\section{DISCUSSION}

\section{Minimal Spillover Across Forest-Plantation Edges}

Our results reveal little evidence that native small mammal communities spill over from forest into adjacent oil palm plantations, and we reject our hypotheses that the majority of native small mammals use the plantation with elevated abundance near the edge, but declining abundance with increasing distance into the plantation. In our oil palm traps we did not capture the three native species (M. surifer, $S$. muelleri, and $N$. cremoriventer) observed at trace abundances in Sabah oil palm plantations by previous studies (Rajaratnam et al., 2007; Bernard et al., 2009), despite a higher number of individuals caught in plantation $(n=91$, Table 1$)$ than these two studies, suggesting that if spillover was occurring, we would probably have detected it. Of the 10 native species trapped in our forest plots, only the small terrestrial murid M. whiteheadi (Whitehead's Rat) occurred in the plantation, being present throughout our distance gradient and plantationinterior control site. This supports previous observations which demonstrate that $M$. whiteheadi appears to be a successful and resilient native competitor to the invasive R. exulans and R. rattus, with populations persisting over long timescales in both heavilylogged forest and plantations (Cusack et al., 2015; Wearn et al., 2016, 2017; Phua et al., 2017; Chapman et al., 2018). Of the native small mammal species that we studied, $M$. whiteheadi therefore appears to be the potential oil palm plantation pest. However, we note that we carried out this study during only one trapping year: small mammal population densities in logged forests tend to be extremely variable, possibly due to underlying resource availability dynamics (Chapman et al., 2018). Since resource scarcity should alter the cost-benefit balance of spilling over into plantations (Luskin et al., 2017), it is possible that repeating our study in multiple years could produce different results.

No studies report $M$. whiteheadi in oil palm plantations outside Sabah, which we suggest may reflect the predominance of pest-control and agricultural literature, and the scarcity of small mammal community studies in Southeast Asian plantations. Plantation murids have been shown to exhibit high temporal turnover and rapid shifts in community composition, for example the dramatic declines of Rattus tiomanicus in peninsular Malaysian plantations during the 1980s, with this species being largely replaced by $R$. rattus (Wood and Fee, 2003). This change was probably mediated by evolution of resistance to chemical rodenticides (Wood and Fee, 2003), so the emergence of $M$. whiteheadi as one of the dominant small mammal species in our studied plantations is potentially both recent and temporary. $M$. whiteheadi populations may also be relatively transient within individual plantations: We found that oil palm tree height (a proxy for plantation age) negatively predicted capture rates for this species and for $R$. exulans. Whether this is due to lower accessibility of oil palm fruit (e.g., Puan et al., 2011), or increased mortality in older plantations (due to enhanced poisoning or decreased vegetative ground cover) is unclear, although capture rates of these species were not predicted by either our measures of ground cover or of fruit availability.

\section{Abundance of $M$. whiteheadi Across the Edge Gradient}

Our data suggest that $M$. whiteheadi remains at high abundance near the edge of forest but declines to a lower constant abundance a mere $23 \mathrm{~m}$ into the plantation. Clearly, direct comparison of capture rates between plantation and forest trap lines is subject to the caveat that we baited our traps with oil palm fruit, a bait which is abundant in the wider plantation, but absent in the forest. Therefore, detectability may be lower within the plantation. Our trapping in this habitat might therefore have underestimated absolute abundance of all species, and possibly altogether missed native species making very occasional feeding forays. Using an alternative bait would not satisfactorily solve this problem, as palm fruit is the most effective available small mammal bait for forest or plantation in this study system (O.R. Wearn, pers. comm. based on a pilot study). Detectability would therefore be similar or lower in a fruit-rich plantation environment if an alternative, less attractive trap bait was used. Conversely, alternative bait might even positively bias our spillover results, if it disproportionately lures species averse to palm fruit into the plantation.

Even if absolute abundance changes between forest and plantation are difficult to measure, if a significant spillover effect occurred over $\geq 23 \mathrm{~m}$ into the plantation, we would still expect elevated capture rates in trap lines close to the edge, relative to the control value, a pattern consistent with plantation populations of $M$. whiteheadi being supplemented with spillover of forest populations across the edge. We found no evidence that this occurred-capture rates were no higher than the control value at our closest plantation sampling point $(23 \mathrm{~m})$. If any spillover did occur and was not detected by this study, it either occurs over distances $<23 \mathrm{~m}$, or represents an extremely minimal net increase in abundance. Similarly, the complete absence of any other native species in the plantation indicates that any undetected spillover of these species is also negligible. The presence of $M$. whiteheadi in both habitats separated by tens of metres suggests that at least some interchange of individuals, and breeding across the edge is likely. However, the absence of observed spillover could reflect two different population-level scenarios: 1 . Relatively unconnected plantation and forest populations, with the edge acting as a significant dispersal barrier; or 2. One highly interconnected population, with relatively free dispersal across the edge countered by high mortality at any distance into the plantation. Confidently distinguishing these scenarios requires a multigenerational study, and much more detailed movement data than we could gather, however we suggest the former scenario may be more likely due to the behavioural aversion to edge crossing we observed, with only one of our 18 tracked $M$. whiteheadi crossing the edge, despite multiple individuals approaching it closely before returning to the forest interior. 
The observed proportion of individuals crossing the edge was no greater than random expectation across any original capture locations, and for individuals captured $\leq 11.5$ from the edge, crossing was significantly less likely than random expectation. We therefore demonstrated that $M$. whiteheadi from inside forest were not significantly attracted to nearby plantations, and are more probably actively repelled by them. Together, this suggests that movement of individuals between populations either side of the forest-plantation edge is relatively rare, and might be limited to occasional, relatively permanent movements (such as postnatal dispersal of juveniles joining the breeding population across the edge), rather than daily foraging movements across the edge, or maintenance of territories covering the edge and including both habitats.

\section{Invasive Small Mammals Across the Gradient}

Although we focussed on the distribution and movement of native small mammal species at the forest-plantation edge, we also found no evidence that forest harbours elevated abundance of the invasive $R$. exulans and $R$. rattus. Both species were present across all our forest trap lines, which supports previous evidence that they can competitively invade logged forest (Cusack et al., 2015; Loveridge et al., 2016; Wearn et al., 2016, 2017). However, capture rates of neither species differed from the plantation control site at any distance. If our use of oil palm baits did cause a bias by reducing relative detectability within the oil palm plantation, true abundances of these species may actually be lower in forest than in the adjacent plantation, and it is possible that these species' persistence in forest adjacent to plantations may depend on spillover from plantations to forest, i.e., the opposite direction to that which we investigated. In general, survival and persistence of invasive murids in selectively-logged Southeast Asian forests is poorly-known, and this is a valuable area for further work.

\section{Conservation Implications}

Our results have important implications for reconciling palm oil agriculture and conservation. First, we showed that under current plantation management strategies (such as existing rodenticide regimes and cleared edge strips), the forestplantation edge represents a largely sufficient barrier to ensure minimal spillover of native small mammals from forest into adjacent plantations. It is therefore unlikely that native small mammals from forest remnants increase damage to crop yields in this agroecosystem close to edges We therefore argue, that this component of forest biodiversity does not provide a valid justification for opposing the conservation of native forest remnants in oil palm landscapes, or for actively removing them. However, terrestrial small mammals only comprise one taxonomic group likely to damage oil palm yields, and further research on other potential pest taxa may reveal much more pronounced spillover. For example, on several occasions during our fieldwork we observed the canopydwelling Plantain Squirrel (Calliosciurus notatus) crossing the edge in places where oil palm trees and adjacent forest vegetation was directly connected, either with interlocking branches or by climbing vines. This squirrel species was not trapped during this study, but has been observed to eat oil palm fruit (Centre for Agriculture and Bioscience International (CABI), 2017), and so an analogous study at canopy level may reveal spillover of this species. Other potential mammalian pests include larger, more dispersive species such as deer, Asian Elephants (Elephas maximus), and Bearded Pigs (Sus barbatus). The latter species left visible trails crossing the edge at several of our sites and are known to persist inside plantations (Yue et al., 2015; Wearn et al., 2017; Love et al., 2018).

Second, although we did not directly examine mortality and population turnover, our results provide little support for the idea that plantations act as a sink habitat for the native small mammal community by attracting individuals out into a highmortality environment. Rather, most forest species appear to be strongly impeded from entering the plantation. The pattern of our captures on the forest side of the edge, with several species not caught within $23 \mathrm{~m}$ of the edge, is more consistent with an edge effect in the opposite direction, although our study was not designed to test for this. We are not aware of any study that explicitly investigates edge effects of oil palm plantations on small mammals in tropical forests, although a camera trapping study of larger mammals (Yue et al., 2015) found no evidence for any effect. Nevertheless, edge effects in small mammals have been observed within other forest-agricultural systems (e.g., Stevens and Husband, 1998; Pardini, 2004), so this is worthy of further investigation. Such edge effects are probably species-specific, and the species we caught are not necessarily those with known high tolerance to deforestation. For example, we captured the specialist squirrels Sundasciurus hippurus and Lariscus hosei, both of which are highly forest dependent and thought to be threatened by habitat degradation and loss (Meijaard and Sheil, 2008). Neither the immediate proximity of an established oil palm plantation, nor the heavy logging at our sample sites, has led to the extirpation of these species from the area.

Overall, however, the apparent aversion of many species to edges, and the resulting low permeability of the oil palm matrix to native small mammals suggests that forest remnants embedded in plantations are likely to host small, reproductively isolated populations of native small mammals, rather than a thriving metapopulation. The harsh environment provided by our studied edges, with a wide strip of bare earth separating forest and plantation ground vegetation cover, and potentially toxic herbicide residues, seems sufficient to confine most forest small mammals within remaining fragments. Over many generations, these communities may simplify and become dominated by the invasive Rattus species, as observed with fragmentation studies on anthropogenic lake islands (e.g., Lynam and Billick, 1999; Gibson et al., 2013). This low landscape permeability may also negatively impact the ability of small mammal species to respond to future environmental change. Our results therefore suggest that maximising connectivity between forest patches may be crucial to maintaining resilience of small mammal communities in fragmented landscapes. 
The persistence in plantations of one native species $(M$. whiteheadi) represents a modest piece of positive news for conservation, and indicates that despite its Vulnerable IUCN classification (IUCN, 2018), M. whiteheadi is unlikely to be at significant risk from anthropogenic habitat change. Nonetheless, M. whiteheadi represents just one out of the 21 terrestrial forest small mammal species in adjacent logged forests (Wearn et al., 2017), so this result does little to alter the overall poor value of plantations for small mammal diversity (Bernard et al., 2009; Wearn et al., 2016, 2017). With a home range radius of $\approx 52 \mathrm{~m}$ (Nakagawa et al., 2007), and considering the aversion of this species to edge crossing, populations persisting in our control site $>1.5 \mathrm{~km}$ into a plantation are probably self-sustaining rather than relying on regular dispersal from a forest-plantation edge. Nevertheless, it is possible that distribution of $M$. whiteheadi in plantations is correlated to forest cover at a regional scale: this may be true if breeding success is marginal, and persistence still requires occasional long-distance gene flow from forests. We also do not know whether $M$. whiteheadi exploits a novel foraging niche in plantations (and potentially causes novel forms of yield damage), or simply displaces the invasive Rattus species. Our expectation is that because $M$. whiteheadi is largely terrestrial (Wells et al., 2004) and appears to be a dietary generalist (Wells et al., 2009), the latter may be more likely.

\section{Management Recommendations and Conclusions}

Our results suggest that under current plantation management routines, there is little ground for conflict between managing oil palm plantations to maintain high yield and conserving adjacent forest areas, as native terrestrial small mammal populations from forests do not spill over forest-plantation edges. Indeed, the "sharp" edges along which we sampled form a sufficiently strong barrier to dispersal to effectively separate small mammal populations from forest and plantations living only tens of metres apart. However, "softer" edges, where vines or other ground vegetation increase connectivity between plantation and forest may enhance small mammal movement across edges, while spillover of other potential pest taxa may prove harder to control. As a precaution, we recommend managers avoid canopy connectivity between forest and plantation by several metres to deter squirrels and other canopy frugivores from crossing the edge. Spillover of larger frugivores such as Bearded Pigs ( $S$. barbatus) may only be controllable by electrified boundary fences of a more substantial design than those used in our sampling areas. However, restricting the movement of these species between fragments, and through the landscape more generally, is likely to significantly impede their persistence by reducing gene flow and restricting access to key foraging areas in forest. We do not therefore recommend the widespread adoption of such fences. In general, the best approach may be to focus on maintaining and restoring connectivity between forest fragments in oil palm landscapes. Creating fewer, larger, more compact, and more interconnected forest areas should help to maximise viability of small and large mammal populations, and reduce the length of edges relative to forest area, limiting negative edge effects on both sides of the edge. In general, our results add to the consensus on the low value of oil palm plantations for biodiversity, and we emphasise that avoiding further expansion of oil palm agriculture at the expense of forest is the optimal approach for conserving mammals and other biodiversity in Southeast Asia and more generally. Nevertheless, real-world conflicts between intensive agriculture and tropical forest conservation are likely to continue occurring in the future, and we believe our results are an important information source for conservation planners and oil palm managers alike, forming a first step towards resolving such future conflicts.

\section{DATA AVAILABILITY}

The raw datasets for the two sections of this study are available on Zenodo, see https://doi.org/10.5281/zenodo.2579791.

\section{AUTHOR CONTRIBUTIONS}

$\mathrm{PC}$ and RE designed the study, with conceptual input from JR, $\mathrm{CC}, \mathrm{CD}$, and HB. HB provided in-country logistical support. PC and $\mathrm{CD}$ collected all field data. RL provided the turning angle and step length data for the null modeling. PC conducted all analyses and wrote the manuscript, with contributions from RE, JR, CC, $\mathrm{CD}, \mathrm{RL}$, and $\mathrm{HB}$.

\section{FUNDING}

This work was funded by the UK Natural Environment Research Council as part of a Ph.D. studentship paid to PC via the Science and Solutions for a Changing Planet Doctoral Training Partnership based at Imperial College London. It was also supported by the Sime Darby Foundation via general support of the SAFE project.

\section{ACKNOWLEDGMENTS}

The authors thank the Sabah Biodiversity Council, Maliau Basin Management Committee, Sabah Forestry Department, and Benta Wawasan Sdn Bhd for research permissions and field access. We also thank Ryan Gray, Suipeng Heon, and the staff of the Stability of Altered Forest Ecosystems Project for logistical support.

\section{SUPPLEMENTARY MATERIAL}

The Supplementary Material for this article can be found online at: https://www.frontiersin.org/articles/10.3389/ffgc.2019. 00002/full\#supplementary-material

Figure S1 | Accumulation curves for (A) species, and (B) individuals, captured during the first section of this study (i.e., excluding individuals captured in the forest trap lines for spool-and-line-tracking). Black lines: forest traps (12 of 48 traps deployed, see Figure 1). Grey lines: oil palm plantation traps (36 of 48 traps deployed). The last three nights where no points are plotted for forest traps refer to the plantation control site: for further details of the trapping design, see the main text. 


\section{REFERENCES}

Almeida, P. J. A. L., Vieira, M. V., Prevedello, J. A., Kajin, M., Forero-Medina, G., and Cerqueira, R. (2015). What if it gets crowded? Density-dependent tortuosity in individual movements of a Neotropical mammal. Austr. Ecol. 40, 758-764 doi: $10.1111 /$ aec. 12250

Amici, A., Serrani, F., Rossi, C. M., and Primi, R. (2012). Increase in crop damage caused by wild boar (Sus scrofa L.): the "refuge effect". Agron. Sustain. Dev. 32, 683-692. doi: 10.1007/s13593-011-0057-6

Andru, J., Cosson, J. F., Caliman, J. P., and Benoit, E. (2013). Coumatetralyl resistance of Rattus tanezumi infesting oil palm plantations in Indonesia. Ecotoxicology 22, 377-386 doi: 10.1007/s10646-012-1032-y

Bates, D., Mächler, M., Bolker, B., and Walker, S. (2015). Fitting linear mixedeffects models using lme4. J. Stat. Softw. 67, 1-48. doi: 10.18637/jss.v067.i01

Bernard, H. (2004). Effects of selective logging on the microhabitat-use patterns of non- volant small mammals in a Bornean tropical lowland mixed-dipterocarp forest. Nat. Hum. Activities 8, 1-11

Bernard, H., Fjeldså, J., and Mohamed, M., (2009). A case study on the effects of disturbance and conversion of tropical lowland rain forest on the non-volant small mammals in north Borneo: management implications. Mamm. Study 34, 85-96. doi: 10.3106/041.034.0204

Blitzer, E. J., Dormann, C. F., Holzschuh, A., Klein, A. M., Rand, T. A., and Tscharntke, T. (2012). Spillover of functionally important organisms between managed and natural habitats. Agric. Ecosyst. Environ. 146, 34-43. doi: 10.1016/j.agee.2011.09.005

Bradshaw, C. J., Sodhi, N. S., and Brook, B. W. (2009). Tropical turmoil: a biodiversity tragedy in progress. Front. Ecol. Environ. 7, 79-87. doi: 10.1890/070193

Brand, L. A., and George, T. L. (2001). Response of passerine birds to forest edge in coast redwood forest fragments. Auk 118, 678-686 doi: 10.1642/00048038(2001)118[0678:ROPBTF]2.0.CO;2

Buckle, A. P., Chia, T. H., Fenn, M. G. P., and Visvalingam, M. (1997). Ranging behaviour and habitat utilisation of the Malayan wood rat (Rattus tiomanicus) in an oil palm plantation in Johore, Malaysia. Crop Protect. 16, 467-473. doi: 10.1016/S0261-2194(97)00010-0

Centre for Agriculture and Bioscience International (CABI) (2017). Plantwise Online Crop Health Knowledge Bank. Available online at: https://www. plantwise.org/ (Accessed November 12, 2017).

Chapman, P. M., Wearn, O. R., Riutta, T., Carbone, C., Rowcliffe, J. M., Bernard, H., et al. (2018). Inter-annual dynamics and persistence of small mammal communities in a selectively logged tropical forest in Borneo. Biodivers. Conserv. 27, 3155-3169. doi: 10.1007/s10531-018-1594-y

Chen, J., Franklin, J. F., and Spies, T. A. (1992). Vegetation responses to edge environments in old-growth Douglas-fir forests. Ecol. Appl. 2, 387-396. doi: $10.2307 / 1941873$

Cusack, J. J., Wearn, O. R., Bernard, H., and Ewers, R. M. (2015). Influence of microhabitat structure and disturbance on detection of native and non-native murids in logged and unlogged forests of northern Borneo. J. Trop. Ecol. 31, 25-35. doi: 10.1017/S0266467414000558

Edwards, F. A., Edwards, D. P., Sloan, S., and Hamer, K. C. (2014). Sustainable management in crop monocultures: the impact of retaining forest on oil palm yield. PLoS ONE 9:e91695. doi: 10.1371/journal.pone.0091695

Ewers, R. M., Didham, R. K., Fahrig, L., Ferraz, G., Hector, A., Holt, R. D., et al. (2011). A large-scale forest fragmentation experiment: the stability of altered forest ecosystems project. Philos. Trans. R. Soc. B Biol. Sci. 366, 3292-3302. doi: 10.1098/rstb.2011.0049

Fitzherbert, E. B., Struebig, M. J., Morel, A., Danielsen, F., Bruhl, C. A., Donald, P. F., et al. (2008). How will oil palm expansion affect biodiversity? Trends Ecol. Evol. 23, 538-545. doi: 10.1016/j.tree.2008.06.012

Forbes, G. J., and Theberge, J. B. (1996). Cross-boundary management of Algonquin Park wolves. Conserv. Biol. 10, 1091-1097. doi: 10.1046/j.1523-1739.1996.10041091.x

Gibson, L., Lee, T. M., Koh, L. P., Brook, B. W., Gardner, T. A., Barlow, J., et al. (2011). Primary forests are irreplaceable for sustaining tropical biodiversity. Nature 478, 378-381. doi: 10.1038/nature10425

Gibson, L., Lynam, A. J., Bradshaw, C. J., He, F., Bickford, D. P., Woodruff, D. S., et al. (2013). Near-complete extinction of native small mammal fauna 25 Years after forest fragmentation. Science 341, 1508-1510. doi: $10.1126 /$ science. 1240495

Hafidzi, M. N., and Saayon, M. K. (2001). Status of rat infestation and recent control strategies in oil palm plantations in Peninsular Malaysia. Pertanika J. Trop. Agric. Sci. 24, 109-114

Hill, C. M. (1997). Crop-raiding by wild vertebrates: the farmer's perspective in an agricultural community in western Uganda. Int. J. Pest Manage. 43, 77-84. doi: 10.1080/096708797229022

Hill, C. M. (2000). Conflict of interest between people and baboons: crop raiding in Uganda. Int. J. Primatol. 21, 299-315. doi: 10.1023/A:1005481605637

Hylander, K. (2005). Aspect modifies the magnitude of edge effects on bryophyte growth in boreal forests. J. Appl. Ecol. 42, 518-525. doi: 10.1111/j.1365-2664.2005.01033.x

IUCN (2018). The IUCN Red List of Threatened Species. Version 2018-1. Available online at: www.iucnredlist.org. Downloaded on 13 August 2018.

Kenwood, R. (2000). A Manual for Wildlife Radio Tagging, $2^{\text {nd }}$ Edn. New York, NY: Academic Press.

Koh, L. P. (2008). Birds defend oil palms from herbivorous insects. Ecol. Appl. 18, 821-825 doi: 10.1890/07-1650.1

Lamb, C. T., Mowat, G., McLellan, B. N., Nielsen, S. E., and Boutin, S. (2017). Forbidden fruit: human settlement and abundant fruit create an ecological trap for an apex omnivore. J. Anim. Ecol. 86, 55-65. doi: 10.1111/1365-2656.12589

Lee, C. H., and Kdmarudin, K. A. (1990). "Rodent species associated to cocoa in Peninsular Malaysia," in Proceedings Third International Conference on Plant Protection in the Tropics, 20-23 March 1990, Genting Highlands (Malaysia: Malaysian Plant Protection Society), 2-7.

Love, K., Kurz, D. J., Vaughan, I. P., Ke, A., Evans, L. J., and Goossens, B. (2018). Bearded pig (Sus barbatus) utilisation of a fragmented forestoil palm landscape in Sabah, Malaysian Borneo. Wildl. Res. 44, 603-612. doi: 10.1071/WR16189

Loveridge, R., Wearn, O. R., Vieira, M., Bernard, H., and Ewers, R. M. (2016). Movement behavior of native and invasive small mammals shows logging may facilitate invasion in a tropical rain forest. Biotropica 48, 373-380. doi: $10.1111 /$ btp. 12306

Lucey, J. L., Tawato, N., Senior, M. J. M., Vun Khen, C., Benedick, S., Hamer, K. C., et al. (2014). Tropical forest fragments contribute to species richness in adjacent oil palm plantations. Biol. Conserv. 169, 268-276. doi: 10.1016/j.biocon.2013.11.014

Luskin, M. S., Brashares, J. S., Ickes, K., Sun, I.-F., Fletcher, C., Wright, S. J., et al. (2017). Cross-boundary subsidy cascades from oil palm degrade distant tropical forests. Nat. Commun. 8:2231. doi: 10.1038/s41467-017-01920-7

Luskin, M. S., Christina, E. D., Kelley, L. C., and Potts, M. D. (2014). Modern hunting practices and wild meat trade in the oil palm plantationdominated landscapes of Sumatra, Indonesia. Hum. Ecol. 42, 35-45. doi: 10.1007/s10745-013-9606-8

Luskin, M. S., and Potts, M. D. (2011). Microclimate and habitat heterogeneity through the oil palm lifecycle. Basic Appl. Ecol. 12, 540-551. doi: 10.1016/j.baae.2011.06.004

Lynam, A. J., and Billick, I. (1999). Differential responses of small mammals to fragmentation in a Thailand tropical forest. Biol. Conserv. 91, 191-200. doi: 10.1016/S0006-3207(99)00082-8

Meijaard, E., and Sheil, D. (2008). The persistence and conservation of Borneo's mammals in lowland rain forests managed for timber: observations, overviews and opportunities. Ecol.Res. 23, 21-34. doi: 10.1007/s11284-007-0342-7

Miles, M. A., De Souza, A. A., and Povoa, M. (1981). Mammal tracking and nest location in Brazilian forest with an improved spool-and-line device. J. Zool. 195, 331-347. doi: 10.1111/j.1469-7998.1981.tb03469.x

Nakagawa, M., Miguchi, H., Sato, K., and Nakashizuka, T. (2007). A preliminary study of two sympatric Maxomys rats in Sarawak, Malaysia: spacing patterns and population dynamics. Raffles Bull. Zool. 55, 381-387.

Naughton-Treves, L. (1998). Predicting patterns of crop damage by wildlife around Kibale National Park, Uganda. Conserv. Biol. 12, 156-168. doi: 10.1046/j.1523-1739.1998.96346.x

Nurdiansyah, F., Denmead, L. H., Clough, Y., Wiegand, K., and Tscharntke, T. (2016). Biological control in Indonesian oil palm potentially enhanced by landscape context. Agric. Ecosyst. Environ. 232, 141-149. doi: 10.1016/j.agee.2016.08.006 
Pardini, R. (2004). Effects of forest fragmentation on small mammals in an Atlantic Forest landscape. Biodivers. Conserv. 13, 2567-2586. doi: 10.1023/B:BIOC.0000048452.18878.2d

Payne, J., and Francis, C. M. (1985). A Field Guide to the Mammals of Borneo. Kota Kinabalu: The Sabah Society.

Pfeifer, M., Kor, L., and Nilus, R., et al (2016). Mapping the structure of Borneo's tropical forests across a degradation gradient. Remote Sens. Environ. 176, 84-97. doi: 10.1016/j.rse.2016.01.014

Phua, M.-H., Chong, C. W., Ahmad, A. H., and Hafidzi, M. N. (2017). Understanding rat occurrences in oil palm plantation using highresolution satellite image and GIS data. Precision Agric. 19:42. doi: 10.1007/s11119-016-9496-Z

Puan, C. L., Goldizen, A. W., Zakaria, M., Hafidzi, M. N., and Baxter, G. S. (2011). Relationships among rat numbers, abundance of oil palm fruit and damage levels to fruit in an oil palm plantation. Integr. Zool. 6, 130-139. doi: 10.1111/j.1749-4877.2010.00231.x

R Core Team (2018). R: A Language and Environment for Statistical Computing. Vienna: R Foundation for Statistical Computing. Available online at: https:// www.R-project.org/

Rajaratnam, R., Sunquist, M., Rajaratnam, L., and Ambu, L. (2007). Diet and habitat selection of the leopard cat (Prionailurus bengalensis borneoensis) in an agricultural landscape in Sabah, Malaysian Borneo. J. Trop. Ecol. 23, 209-217. doi: $10.1017 /$ S0266467406003841

Rand, T. A., Tylianakis, J. M., and Tscharntke, T. (2006). Spillover edge effects: the dispersal of agriculturally subsidized insect natural enemies into adjacent natural habitats. Ecol. Lett. 9, 603-614. doi: 10.1111/j.1461-0248.2006.00911.x

Reynolds, G., Payne, J., Sinun, W., Mosigil, G., and Walsh, R. P. (2011). Changes in forest land use and management in Sabah, Malaysian Borneo, 1990-2010, with a focus on the Danum Valley region. Philos. Trans. R. Soc. Lond. B. Biol. Sci. 366, 3168-3176. doi: 10.1098/rstb.2011.0154

Saj, T. L., Sicotte, P., and Paterson, J. D. (2001). The conflict between vervet monkeys and farmers at the forest edge in Entebbe, Uganda. Afr. J. Ecol. 39, 195-199. doi: 10.1046/j.0141-6707.2000.00299.x

Sikes, R. S., Gannon, W. L., and Animal Care And Use Committee of the American Society of Mammalologists (2011). Guidelines of the American Society of Mammalogists for the use of wild mammals in research. J. Mammal. 92, 235-253. doi: 10.1644/10-MAMM-F-355.1

Stevens, S. M., and Husband, T. P. (1998). The influence of edge on small mammals: evidence from Brazilian Atlantic forest fragments. Biol. Conserv. 85, 1-8. doi: 10.1016/S0006-3207(98)00003-2

Strum, S. C. (2010). The development of primate raiding: implications for management and conservation. Int. J. Primatol. 31, 133-156. doi: 10.1007/s10764-009-9387-5

Tweheyo, M., Hill, C. M., and Obua, J. (2005). Patterns of crop raiding by primates around the Budongo Forest Reserve, Uganda. Wildlife Biol. 11, 237-248. doi: 10. 2981/0909-6396(2005)11[237:POCRBP]2.0.CO;2

Valantin-Morison, M., Meynard, J. M., and Doré, T. (2007). Effects of crop management and surrounding field environment on insect incidence in organic winter oilseed rape (Brassica napus L.). Crop Protect. 26, 1108-1120. doi: 10.1016/j.cropro.2006.10.005

Vijay, V., Pimm, S. L., Jenkins, C. N., and Smith, S. J. (2016). The impacts of oil palm on recent deforestation and biodiversity loss. PLOS ONE 11:e0159668. doi: 10.1371/journal.pone.0159668

Wearn, O. R., Carbone, C., Rowcliffe, J. M., et al. (2016). Grain-dependent responses of mammalian diversity to land use and the implications for conservation set-aside. Ecol. Appl. 26, 1409-1420. doi: 10.1890/15-1363

Wearn, O. R., Rowcliffe, J. M., and Carbone, C., et al (2017). Mammalian species abundance across agradient of tropical land-use intensity: a hierarchical multi-species modelling approach. Biol. Conserv. 212, 162-171. doi: 10.1016/j.biocon.2017.05.007

Wells, K., Corlett, R. T., Lakim, M. B., Kalko, E. K., and Pfeiffer, M. (2009). Seed consumption by small mammals from Borneo. J. Trop. Ecol. 25, 555-558. doi: $10.1017 /$ S0266467409990058
Wells, K., Kalko, E. K., Lakim, M. B., and Pfeiffer, M. (2007). Effects of rain forest logging on species richness and assemblage composition of small mammals in Southeast Asia. J. Biogeogr. 34, 1087-1099. doi: 10.1111/j.1365-2699.2006.01677.x

Wells, K., Lakim, M. B., and Pfeiffer, M. (2008). Movement patterns of rats and treeshrews in Bornean rainforest inferred from mark-recapture data. Ecotropica 14, 113-120.

Wells, K., Pfeiffer, M., Lakim, M. B., and Kalko, E. K. (2006). Movement trajectories and habitat partitioning of small mammals in logged and unlogged rain forests on Borneo. J. Anim. Ecol. 75, 1212-1223. doi: 10.1111/j.1365-2656.2006.0 1144.x

Wells, K., Pfeiffer, M., Lakim, M. B., and Linsenmair, K. E. (2004). Use of arboreal and terrestrial space by a small mammal community in a tropical rain forest in Borneo, Malaysia. J. Biogeogr. 31, 641-652. doi: 10.1046/j.1365-2699.2003.01032.x

White, J., Wilson, J., and Horskins, K. (1997). The role of adjacent habitats in rodent damage levels in Australian macadamia orchard systems. Crop Protect. 16, 727-732. doi: 10.1016/S0261-2194(97)00062-8

Wilcove, D. S., Giam, X., Edwards, D. P., Fisher, B., and Koh, L. P. (2013). Navjot's nightmare revisited: logging, agriculture, and biodiversity in Southeast Asia. Trends Ecol. Evol. 28, 531-540. doi: 10.1016/j.tree.2013. 04.005

Wood, B. J. (1984). A long-term study of Rattus tiomanicus populations in an oil palm plantation in Johore, Malaysia: I. Study methods and population size without control. J. Appl. Ecol. 21, 445-464. doi: 10.2307/24 03421

Wood, B. J. (1994). "Rodents in agriculture and forestry," in Rodent Pests and Their Control, eds A. P. Buckle and R. H. Smith (Oxon: CAB International), 45-83.

Wood, B. J., and Chung, G. F. (1990). "Warfarin resistance of Rattus tiomanicus in oil palms in Malaysia and the associated increase of Rattus diardii," in Proceedings of The Fourteenth Vertebrate Pest Conference 1990, eds L. R. Davis and R. E. Marsh (Sacramento: University of California, Davis).

Wood, B. J., and Fee, C. G. (2003). A critical review of the development of rat control in Malaysian agriculture since the 1960s. Crop Protect. 22, 445-461. doi: 10.,1016/S0261-2194(02)00207-7

Wood, B. J., and Liau, S. S. (1984a). A long-term study of Rattus tiomanicus populations in an oil palm plantation in Johore, Malaysia: II. Recovery from control and economic aspects. J. Appl. Ecol. 21, 465-472. doi: 10.2307/24 03422

Wood, B. J., and Liau, S. S. (1984b). A long-term study of Rattus tiomanicus populations in an oil palm plantation in Johore, Malaysia: III. Bionomics and natural regulation. J. Appl. Ecol. 21, 473-495. doi: 10.2307/24 03423

Woodroffe, R., and Ginsberg, J. R. (1998). Edge effects and the extinction of populations inside protected areas. Science 280, 2126-2128. doi: 10.1126/science.280.5372.2126

Yue, S., Brodie, J. F., Zipkin, E. F., and Bernard, H. (2015). Oil palm plantations fail to support mammal diversity. Ecol. Appl. 25, 2285-2292. doi: 10.1890/14-1928.1

Zhang, W., Ricketts, T. H., Kremen, C., Carney, K., and Swinton, S. M. (2007). Ecosystem services and dis-services to agriculture. Ecol. Econ. 64, 253-260 doi: 10.1016/j.ecolecon.2007.02.024

Conflict of Interest Statement: The authors declare that the research was conducted in the absence of any commercial or financial relationships that could be construed as a potential conflict of interest.

Copyright (C) 2019 Chapman, Loveridge, Rowcliffe, Carbone, Bernard, Davison and Ewers. This is an open-access article distributed under the terms of the Creative Commons Attribution License (CC BY). The use, distribution or reproduction in other forums is permitted, provided the original author(s) and the copyright owner(s) are credited and that the original publication in this journal is cited, in accordance with accepted academic practice. No use, distribution or reproduction is permitted which does not comply with these terms. 